\title{
Colloid Centrifugation of Semen: Applications in Assisted Reproduction
}

\author{
Jane M. Morrell1 ${ }^{*}$, Heriberto Rodriguez-Martinez ${ }^{2}$ \\ ${ }^{1}$ Division of Reproduction, Clinical Sciences, Swedish University of Agricultural Sciences, \\ Uppsala, Sweden \\ ${ }^{2}$ Division of Clinical Sciences/O\&G, Department of Clinical and Experimental Medicine, Linköping University, \\ Linköping, Sweden \\ Email: "jane.morrell@slu.se
}

Received 20 June 2016; accepted 24 July 2016; published 27 July 2016

Copyright () 2016 by authors and Scientific Research Publishing Inc.

This work is licensed under the Creative Commons Attribution International License (CC BY).

http://creativecommons.org/licenses/by/4.0/

(c) (i) Open Access

\begin{abstract}
Colloid centrifugation can be used to separate heterogeneous populations of cells particularly semen samples, which typically contain mixtures of spermatozoa at different stage of maturity together with dead and dying spermatozoa and also non-sperm cells. Colloids can be used to enrich the population of spermatozoa that are viable and functional; these are the spermatozoa that are needed for fertilization in Assisted Reproduction. Sperm samples obtained after colloid centrifugation may be enriched for motile, morphologically normal spermatozoa with intact chromatin. Insemination of mares with stallion sperm samples prepared by colloid centrifugation resulted in a higher pregnancy rate per cycle than controls, confirming that the good sperm attributes observed in the laboratory were indicative of functional spermatozoa. The method does not simply enrich for viable spermatozoa by inhibiting dead or dying spermatozoa from passing through the colloid since emerging evidence shows that colloid centrifugation can select for spermatozoa with certain properties such as metabolic activity. Other reproductive cells, such as spermatids or progenitor cells, may also be purified by colloid centrifugation. This review describes the history of colloid centrifugation for selecting spermatozoa, compares colloid centrifugation with alternative techniques, and finally describes some of the applications of the technique within the animal breeding industry.
\end{abstract}

\section{Keywords}

Animal Spermatozoa, Purification, Enrichment, Selection, Spermatids

*Corresponding author. 


\section{Introduction}

Colloid centrifugation is a technique for separating different types of cells from heterogeneous suspensions [1]. One specialised application of this technique is in selecting spermatozoa for various assisted reproduction techniques i.e. where a pregnancy is created by a means other than natural mating. The most commonly encountered technique of assisted reproduction in animals is artificial insemination (AI); in Europe the vast majority of dairy cattle and pigs are bred using this technique [2]. Specialist laboratories may use in vitro fertilization (IVF), particularly for cattle, where sperm samples are added to oocytes in the laboratory and incubated to allow the fertilized oocytes to develop; and intracytoplasmic sperm injection (ICSI) e.g. in horses, where an individual spermatozoon is injected into an oocyte. The embryos generated by these processes can be transferred to recipients to create a pregnancy, either immediately or after cryopreservation and storage. These techniques are also adopted occasionally for conservation management i.e. the breeding of rare or endangered species. In contrast, human fertility treatments usually involve IVF or ICSI rather than intrauterine insemination. Regardless of the assisted reproductive technology (ART) that is to be employed, colloid centrifugation can be used to obtain functional spermatozoa, thereby increasing the chances of generating a pregnancy [3] and for that pregnancy to continue [4]. In addition to practical applications in ART, colloid centrifugation is a useful research tool in the elucidation of the mechanisms occurring in spermatozoa during maturation, capacitation and the acrosome reaction. These events are all necessary before spermatozoa can bind to the zona pellucida prior to fertilization of the oocyte.

If cell suspensions are centrifuged through colloids of different densities, the cells move to a point that matches their own density-the isopycnic point [1]. The degree of separation that can be achieved depends on how many layers of colloid of different densities are used and the differences in densities of the various cells that are to be separated. When colloids are used to separate sperm samples, it is usual to choose a colloid that is less dense than mature sperm cells so that the spermatozoa will pellet in the bottom of the centrifuge tube for ease of retrieval.

Colloid centrifugation may be used to select and purify epididymal spermatozoa [5] or precursor cells such as round and elongated spermatids [6], or even spermatogonia - the progenitor cells that will form spermatocytes at the start of spermatogenesis. Occasionally it may be necessary to use epididymal spermatozoa, either post-castration or after the death of the animal [7]. This is particularly relevant for conservation biology, when recovery of epididymal and testicular spermatozoa may represent the last chance to recover genetic material from a particular individual. However, such tissue is usually contaminated with blood and cellular debris, both of which have a detrimental effect on sperm survival. Transplantation of spermatogonial stem cells to other individuals has been achieved in mice and bulls [8], with production of donor gametes from the recipient, but extraction of the spermatogonia requires enrichment of the specific cells from a mixture of testicular cells.

This review will describe sperm selection by colloid centrifugation and compare this method to other sperm selection methods that have been reported. Species-specific applications of colloid centrifugation will be discussed, particularly for the equine, porcine and bovine breeding industries, as well as in conservation breeding

\section{Sperm Selection}

Spermatozoa to be used for ART must be functional i.e. able to fertilize an oocyte and to direct the future development of the zygote. Semen samples contain a heterogeneous mixture of spermatozoa at different stages of maturity and functional ability. Colloid centrifugation enables a sub-population to be selected consisting mainly of motile spermatozoa with intact membranes, stable DNA and normal morphology, and to separate them from the rest of the ejaculate [9]. These attributes of sperm quality have been associated with an increased likelihood of pregnancy [10]; therefore, selected sperm samples are more likely to generate a pregnancy than unselected samples. This process mimics the selection that is believed to occur in the female reproductive tract, where spermatozoa swim away from the seminal plasma at the site of semen deposition and then are subjected to selection at various sites in the reproductive tract, for example by selective binding to oviductal epithelial cells [11]. Since colloid centrifugation mimics a biological process, it is known as a biomimetic technique [3].

\section{Colloid Centrifugation of Spermatozoa}

Before spermatozoa can fertilize an oocyte, they must undergo a series of membrane changes, known as capaci- 
tation, followed by the acrosome reaction just before they bind to the oocyte. The timing of these events is crucial because spermatozoa do not survive long after undergoing the acrosome reaction. Thus, the provision of a mixture of spermatozoa of different ages in the ejaculate is to ensure that there will be a progression of spermatozoa capable of fertilization in the oviducts over a period of time under physiological conditions. However, if the sperm sample is to be stored prior to being inseminated into a female, the presence of cellular debris and dead or dying spermatozoa may adversely affect the viable spermatozoa. Separation of the latter from the rest of the ejaculate therefore enables them to remain functional over a longer period of time during in vitro storage. A further advantage is that spermatozoa can be removed from seminal plasma (which contains decapacitating factors) and semen extender before use [12], thus enabling them to be used for IVF. Colloid centrifugation may select for spermatozoa with longer telomeres than in control samples; telomeres are believed to play a key role in early embryonic survival [13].

In colloid centrifugation, a sub-population of motile spermatozoa with normal morphology, intact membranes and good chromatin integrity is separated from the rest of the ejaculate, including the seminal plasma [3]. These spermatozoa pass through the colloid during gentle centrifugation and form a pellet in the bottom of the centrifuge tube, whereas non-motile spermatozoa or those with damaged chromatin are retained at the interface between the semen and the colloid [14]. Seminal plasma, with its content of non-sperm cells and microorganisms, such as bacteria, and semen extender are retained above the colloid. Typically, the selected spermatozoa in the pellet will exhibit better sperm quality than in the original unselected sample [9] [15], and will retain this quality [16] and fertilizing ability [17] for longer than those in the original samples. If too many spermatozoa are loaded on to the colloid, or high numbers of abnormal spermatozoa are present at the interface, some normal spermatozoa will be unable to pass into the colloid and will be found in the interface population. The centrifugation force and time, as well as the physical properties of the colloid [14] are critical in allowing as many normal spermatozoa as possible to reach the pellet while preventing immotile or morphologically abnormal spermatozoa from entering the colloid.

The colloids typically used to prepare spermatozoa are coated silica colloids e.g. Percoll (polyvinylpyrrolidone-coated silica), prepared in a buffered salt solution. When Percoll is used, buffered salt solutions are used to dilute the colloid to achieve the desired density. The dilutions must be made up just prior to use since they are not stable. In contrast, silane-coated silica e.g. Redigrad, is stable in solution and can be made up well in advance of use. Silane-coated silica colloids are available as ready-to-use formulations specifically for sperm selection. The salt composition, $\mathrm{pH}$, osmolarity and density of the colloid formulation affect the outcome of centrifugation in terms of number of spermatozoa in the pellet and their quality [14]. Commercial colloid products are sterilized during manufacture, and typically do not contain antibiotics. Other substances may also be used e.g. Iodixanol (OptiPrep ${ }^{\mathrm{TM}}$, Progen, Heidelberg, Germany) [18].

\section{Background to Sperm Selection by Colloid Centrifugation}

\subsection{Density Gradient Centrifugation}

The first application of colloid centrifugation to sperm selection was as a density gradient, in which two or more layers of colloids of different densities were used e.g. [19]. The degree of separation achieved depends on the difference in density of the colloids used in the gradient and the difference in densities of the cells to be separated. The technique gained popularity for preparing human semen in fertility clinics, since the volume of semen to be processed was generally small and the sperm concentration low. Typically the volume of colloid in each layer was 1 - $2 \mathrm{~mL}$, depending on the number of layers used, and the volume of semen to be processed was approximately $1.5 \mathrm{~mL}$. The technique had severe limitations when trying to process animal semen which typically has much larger volumes and higher sperm concentrations than human semen. Nevertheless, this technique was also used for preparing frozen animal semen (mostly bovine) for IVF e.g. [20]. Although sperm quality in animal semen could be improved by DGC in the laboratory, the consensus of opinion was that it was too impractical for processing whole ejaculates for AI in the field.

In the1990s, a debate occurred concerning whether Percoll ${ }^{\mathrm{TM}}$ was harmful to spermatozoa, with some researchers reporting adverse effects from the use of PVP-coated silica (e.g. [21]. However, PVP has been used to facilitate the capture of bovine spermatozoa for ICSI without any detrimental effects on the spermatozoa [22]. Subsequently, there were reports of problems with mouse zygote development following exposure of spermatozoa to PVP [23]. These conflicting results may be due to species differences in susceptibility to PVP or may re- 
flect differences in the PVP from various sources [24]. Subsequently, some batches of Percoll were found to have high endotoxin levels [25], necessitating the testing of each batch to identify those suitable for use with sperm samples. Other problems potentially associated with the use of PVP-coated silica include structural alterations in human spermatozoa [26], although these were observed after exposure to $10 \% \mathrm{PVP}$, a high concentration per se.

Commercially available colloid formulations for DGC of semen became available early in the $21^{\text {st }}$ century. Stallion sperm quality was improved in the selected samples [27] and the technique could be used to prepare small numbers of spermatozoa from problem ejaculates for low dose insemination [28]. However, sperm yields were too low and the method too impractical for routine application when preparing spermatozoa for conventional insemination in the field.

\subsection{Centrifugation Though a Single Layer of Colloid}

Towards the end of the 1990s, a modification of DCG was developed utilizing one layer of Percoll ${ }^{\mathrm{TM}}$ for preparing human spermatozoa [29]. Good results were obtained with oligospermic ejaculates but the sperm quality of normospermic semen was not improved. Thus the technique was not considered to be useful at that time, since there was a preference to have a standard protocol for all sperm samples. Similar results were later reported when one layer of Percoll ${ }^{\mathrm{TM}}$ was tested with stallion semen [30], with sperm quality being improved only in poor quality ejaculates.

Single Later Centrifugation (SLC) using one layer of a species-specific colloid for stallion spermatozoa (Androcoll-E) was reported by Morrell et al. [31]. The advantage of using only one layer of colloid is that the protocol is less time-consuming and easier to use than DGC. The same authors described a series of studies in which "normal" stallion ejaculates were split and processed by DGC and SLC. Sperm quality was improved in both types of selected samples compared to the uncentrifuged samples, and there was no difference in sperm quality between the two colloid centrifugation groups [9] [14]. Results from 250 ejaculates processed by SLC showed that the technique was repeatable and reliable under field conditions for stallion ejaculates at commercial stud farms [16]. In addition, development of a different colloid formulation for use in $50 \mathrm{~mL}$ tubes (Androcoll-E Large) enabled SLC to be scaled-up to process whole stallion ejaculates in 4 - 6 of these $50 \mathrm{~mL}$ tubes [32]. It would be too laborious to attempt to use DGC in this size of tube. This scaled-up technique has been slowly gaining popularity around the world, particularly for processing problem stallion ejaculates.

It is also possible to use SLC to process $25 \mathrm{~mL}$ of extended semen in $100 \mathrm{~mL}$ tubes or even $150 \mathrm{~mL}$ extended semen in $500 \mathrm{~mL}$ tubes [33]. The latter is particularly useful for processing boar ejaculates, which are voluminous. Thus protocols and colloids have been developed for the following sizes of tubes: $15 \mathrm{~mL}, 50 \mathrm{~mL}, 100 \mathrm{~mL}$, $500 \mathrm{~mL}$ [34]. For optimum results, the specific colloid formulation for a particular size of tube should be used. These modifications in the SLC methodology are shown in Table 1.

The SLC technique was also modified to process small volumes of thawed bull semen. Whereas some studies were reported in which $1 \mathrm{~mL}$ of colloid was used in a microcentrifuge tube with a small volume of semen e.g. [35], it was found that a higher yield of spermatozoa cold be obtained using $1 \mathrm{ml}$ of colloid in a $15 \mathrm{~mL}$ tube [36].

\begin{tabular}{|c|c|c|c|}
\hline Tube size & $\begin{array}{c}\text { Volume } \\
\text { colloid (mL) }\end{array}$ & $\begin{array}{l}\text { Volume extended } \\
\text { semen }^{*}(\mathrm{~mL})\end{array}$ & Reference \\
\hline $12-15 \mathrm{~mL}$ & 1.0 & 0.25 & [36] \\
\hline $12-15 \mathrm{~mL}$ & 4.0 & Up to 4.5 & [32] \\
\hline $50 \mathrm{~mL}$ & 15 & Up to 20 & [32] [33] [59] \\
\hline $100 \mathrm{~mL}$ & 20 & 25 & [33] \\
\hline $200 \mathrm{~mL}$ & 60 & 60 & [32] \\
\hline $500 \mathrm{~mL}$ & 150 & 150 & [33] \\
\hline
\end{tabular}

* Optimal sperm concentration of up to $100 \times 10^{6}$ is appropriate for boar and stallion semen; for bull semen, $50 \times 10^{6} / \mathrm{mL}$ should be used. 
The silane-coated silica colloid is expensive, and therefore being able to use smaller volumes is attractive on economic grounds.

\section{Selection or Enrichment?}

Several researchers have argued that in fact there is no selection of particular sub-populations, only an enrichment of viable, motile spermatozoa by separating them from dead or dying spermatozoa. There is some evidence that colloid centrifugation does result in selection of spermatozoa; in a recent publication, Morrell et al. [37] showed that sperm samples after SLC had a different pattern of reactive oxygen species (ROS) production than uncentrifuged samples. The SLC-samples showed a significantly reduced production of hydrogen peroxide compared to controls, whereas the production of superoxide was slightly increased. These results are intriguing, since it is commonly believed that superoxide radicals are rapidly converted to hydrogen peroxide. These results suggest that either superoxide is not converted to hydrogen peroxide, as previously, thought or that SLC may allow the passage of a sperm sub-population that metabolise differently to the main population. In the latter case, it would suggest that selection of spermatozoa with certain properties is being achieved. However, whether the mechanism of colloid centrifugation is selection or enrichment, the end result is that a sperm sample is produced that survives longer than controls, may have better chromatin integrity and morphology than controls and, at least in horses, results in a higher pregnancy rate after AI.

\section{Alternative Methods for Selecting Spermatozoa}

Alternative sperm selection techniques include migration (where spermatozoa move from the sample into medium), and filtration through Sephadex. Migration techniques select for motile spermatozoa, but these spermatozoa may be morphologically abnormal or have damaged chromatin. The sperm recovery rate is low, being approximately $10 \%$, the method is time-consuming and requires an incubator or at least a water bath in which the tube containing the sample can be placed at an angle. Sephadex purportedly selects for motile, morphologically normal spermatozoa with intact acrosomes. However, neither of these techniques has been adapted for routine field use. In addition, a sperm washing technique is used to remove most of the seminal plasma from the sperm sample. This technique does not select a sperm sub-population but may prolong sperm life during storage [38], although other authors have observed an increase in sperm chromatin damage after this type of handling. A comparison of these different techniques, including sperm washing and colloid centrifugation, is described in detail in [3] and is summarized in Table 2, modified from [3]. The species in which these techniques have been tested are listed in Table 3 . A brief description of the most commonly tested techniques follows.

\subsection{Sperm Washing}

This method separates the spermatozoa from seminal plasma [39] and extender such as cryopreservation medium. Semen extender is added to the semen which is then centrifuged gently; the supernatant is removed and the sperm pellet resuspended in medium or fresh semen extender. Most of the spermatozoa that were present in the original sample are found in the sperm pellet, together with dead and abnormal spermatozoa and cellular debris [40]. However, there are some reports that the most motile spermatozoa may swim-up again from the sperm pellet while the centrifuge is decelerating, and are thus discarded with the supernatant. Up to $20 \%$ of the most motile spermatozoa may be lost through this route [41]. Sources of reactive oxygen species are not removed; these may be detrimental to sperm viability or may cause chromatin damage. In an effort to reduce the number of spermatozoa lost, a modification of the sperm washing technique is to use cushion fluid in the bottom of the centrifuge tube. A dense material is layered under the sperm sample before centrifugation, through which the spermatozoa cannot pass; thus the cushion fluid acts as a buffer between the spermatozoa and the walls of the centrifuge tube allowing the sample to be centrifuged at a much higher $\mathrm{g}$ force than where there is no cushion fluid. However, such samples also contain more damaged chromatin than samples prepared by other methods [42], suggesting that increasing the centrifugal force is not necessarily problem-free.

In a modification of the washing technique, low-molecular weight components of seminal plasma have been removed from boar ejaculates by dialysis [43]. More recently, a sperm filter similar to a coffee filter was reported to separate spermatozoa from seminal plasma without the need for centrifugation [44]. The recovery rate after the sperm filter was greater than after sperm washing (89\% versus $81 \%$ ). 
Table 2. Properties of different sperm separation and selection methods (modified from [3]).

\begin{tabular}{|c|c|c|c|c|}
\hline Property & Washing; simple filters & Migration e.g. swim-up & Filtration & Colloid centrifugation \\
\hline Ease of use & Simple & & & $\begin{array}{l}\text { Requires some } \\
\text { attention to detail }\end{array}$ \\
\hline Equipment required & Centrifuge & $\begin{array}{l}\text { Special tubes needed } \\
\text { for swim-through }\end{array}$ & & Centrifuge \\
\hline Consumables & Centrifuge tubes & $\begin{array}{l}\text { Special tubes needed for } \\
\text { migration/sedimentation }\end{array}$ & $\begin{array}{c}\text { Glass wool, Sephadex, } \\
\text { filters }\end{array}$ & Colloids \\
\hline Cost per sample & Lowest & $\begin{array}{l}\text { Low, unless media } \\
\text { contains hyaluronate }\end{array}$ & Higher & Highest \\
\hline Sperm selection & None & Based only on motility & $\begin{array}{l}\text { Based on motility, } \\
\text { morphology, intact } \\
\text { acrosomes }\end{array}$ & $\begin{array}{l}\text { Based on motility, } \\
\text { morphology, viability, } \\
\text { chromatin integrity, } \\
\text { acrosome integrity. }\end{array}$ \\
\hline Seminal plasma removed & Mostly & Yes & Some removed & Yes \\
\hline $\begin{array}{l}\text { Pathogens and } \\
\text { debris removed }\end{array}$ & No & ? & ? & Yes \\
\hline $\begin{array}{l}\text { Yield of motile } \\
\text { spermatozoa }\end{array}$ & ? & $10 \%-20 \%$ & ca. $60 \%-85 \%$ & $>50 \%$ \\
\hline Leukocytes & Present & Removed & Removed & Removed \\
\hline Acrosome & Unknown effect & May be damaged & Increased \% intact & Increased \% intact \\
\hline Other & & $\begin{array}{l}\text { Hyaluronate-containing } \\
\text { media may induce } \\
\text { acrosome reaction }\end{array}$ & $\begin{array}{l}\text { Contamination by } \\
\text { e.g. glass fibres }\end{array}$ & $\begin{array}{l}\text { Possible problems with } \\
\text { Percoll }{ }^{\mathrm{TM}} \text { (endotoxin } \\
\text { levels, PVP etc) }\end{array}$ \\
\hline Animal & $\begin{array}{l}\text { Buffalo, ram, boar, } \\
\text { stallion }\end{array}$ & Bull, ram, boar, dog & Ram, boar, buffalo, bull & $\begin{array}{l}\text { Bull, ram, boar, stallion, } \\
\text { turkey, dog, leopard }\end{array}$ \\
\hline
\end{tabular}

Table 3. Examples of sperm preparation techniques used in various species.

\begin{tabular}{|c|c|c|c|}
\hline Sperm washing & Migration e.g. swim-up & $\begin{array}{l}\text { Filtration e.g. glass wool, } \\
\text { sephadex }\end{array}$ & Colloid centrifugation \\
\hline $\begin{array}{c}\text { Buffalo [76] } \\
\text { Ram [77] } \\
\text { bull [78] } \\
\text { Boar [79] } \\
\text { Stallion [80] [81] }\end{array}$ & $\begin{array}{c}\text { Bull [40] [44] [78] [82] [83] } \\
\text { Ram [77] [84] } \\
\text { Boar [85] } \\
\text { Buffalo [76] [86] } \\
\text { Stallion [30] }\end{array}$ & $\begin{array}{c}\text { Ram [77] } \\
\text { Boar [87] } \\
\text { Buffalo [50] [75] } \\
\text { Stallion [51] [88] [89] } \\
\text { Bull [74]-[76] [90] } \\
\text { Dog [48] }\end{array}$ & $\begin{array}{c}\text { Bull [45] [78] [82] } \\
\text { Ram [77] } \\
\text { Boar [62] [91] } \\
\text { Stallion [92] } \\
\text { Turkey [93] } \\
\text { Dog [94] } \\
\text { Goat [69] } \\
\text { Red deer [33] } \\
\text { Donkey [70] } \\
\text { Brown bear [71] } \\
\text { Cat [53] [72] } \\
\text { Gray wolf [74] } \\
\text { Camel [95] }\end{array}$ \\
\hline
\end{tabular}

\subsection{Sperm Migration}

Migration techniques rely on the ability of spermatozoa to move from the extended ejaculate or washed sperm pellet into another medium [25], thereby separating themselves from seminal plasma. The sperm sample can be underneath, on top of, or to one side of the second medium into which the spermatozoa will swim [25], although the most common arrangement is to have the sperm sample underneath (hence the name "swim-up"). Selection is based on motility; there is no selection for other parameters of sperm quality such as head morphology, viability, acrosome status or chromatin integrity [45]. Sperm samples may exhibit better midpiece- and tail-morphology after swim-up than after sperm washing, e.g. [40] because tail abnormalities may hinder motility and the spermatozoa 
are therefore retained in the original sample. Migration through, media containing hyaluronic acid may select for spermatozoa with intact membranes [46] [47]. The major disadvantage of migration methods is the low recovery rate, e.g. $10 \%$ - 20\% [40] thus making it impractical for preparing AI doses in most animal species, although it can be a useful technique for separating spermatozoa from seminal plasma prior to IVF.

\subsection{Sperm Filtration}

Substances such as glass wool and Sephadex beads have been used to select motile, viable spermatozoa with intact acrosomes [48]. Non-viable spermatozoa tend to adhere to the matrix more than motile spermatozoa [49]. The mechanism of action is unclear but may involve adherence of abnormal spermatozoa to the matrix due to surface charges [50], or proteins present on the sperm surface after capacitation [51]. Bull spermatozoa are reported to show improved freezability after Sephadex filtration [52]. Such methods help to eliminate leukocytes (and thus some sources of ROS) and fewer spermatozoa are lost than with other methods, e.g. a recovery rate of approximately $63 \%$ was reported by [53]. However, the filtrate is not as clean as with other sperm separation methods [53], because not all of the seminal plasma and cellular debris is removed.

\subsection{Additional Selection Techniques}

Newer technologies, such as microfluidics, electrophoresis, motile sperm organelle morphology examination (MSOME), and birefringence have been advocated for processing human semen [54]. One example is that the microfluidic device was used to select spermatozoa with better chromatin fragmentation, as evaluated by the DNA dispersion test, from oligospermic human samples [55]. However, such methods are too expensive and impractical to be considered for processing animal semen. In addition, the authors claim that eliminating the centrifugation steps should improve the selection of sperm with higher motility, normal morphology and DNA integrity, whereas colloid centrifugation achieves all these outcomes if performed correctly.

\section{How to Perform Single Layer Centrifugation}

The following directions for use apply to species-specific colloids developed by the authors, previously known as Androcoll with a suffix denoting the species e.g. Androcoll-E was for the equine species. It should be noted that the protocol has been developed only for this colloid formulation [32]; other colloid formulations may not give such good results.

The ready-to-use colloid should be equilibrated to room temperature before use, to avoid cold-shocking the spermatozoa. The colloid is poured into the centrifuge tube and the semen sample, adjusted to the appropriate sperm concentration (e.g. $100 \times 10^{6} / \mathrm{mL}$ for boar and stallion; $50 \times 10^{6} / \mathrm{mL}$ for bull), is pipetted on top to form a distinct separate layer. The semen should be added slowly so that the interface between the colloid and semen is not disrupted. The tube is placed in the centrifuge at $300 \times g$ for 20 minutes. The centrifuge should preferably have a swing-out rotor and the brake should not be used i.e. the centrifuge should be allowed to slow down gently at the end of the centrifugation time. The supernatant is removed carefully: first the seminal plasma and extender, then the interface layer (containing spermatozoa that have not passed into the colloid), and lastly the colloid, down to the last $1-2 \mathrm{~mm}$ above the sperm pellet. Using a clean pipette, the sperm pellet is retrieved from beneath the colloid and placed in a clean tube for suspension in semen extender to the desired concentration.

\section{Practical Applications of SLC}

Apart from sperm washing, which does not select spermatozoa, SLC is the only sperm selection technique that is used in the field. The recovery rate is linked to the quality of the original sperm sample, typically ranging from $20 \%$ - $90 \%$ with a mean recovery of $>50 \%$. Practical applications of SLC for equine spermatozoa have been reported previously [56]; however, applications of SLC for other species have not been reviewed. The following section describes some of these applications in livestock species and for conservation breeding.

\subsection{Preparing Spermatozoa for Artificial Insemination}

Pregnancy rates after AI are known to be linked to sperm quality in the ejaculate [10]; therefore, selecting the 
most motile, morphologically normal spermatozoa with intact chromatin should, theoretically, result in a higher pregnancy rate after AI. This was found to be the case in an AI trial in horses, in which insemination of SLCselected sperm samples resulted in significantly more pregnancies than unselected control samples [57]. The SLC-selected stallion sperm samples also retain motility, viability and chromatin integrity in storage at $6^{\circ} \mathrm{C}$, which unselected controls do not [58]. The SLC samples were still fertile $96 \mathrm{~h}$ after semen collection and selection, whereas unselected semen usually cannot be stored for more than $36 \mathrm{~h}$ after semen collection. The pattern of ROS-production is changed in the selected samples, with significantly less production of hydrogen peroxide in the SLC-selected samples than in unselected controls. This observation may help to explain the apparently longer life of the SLC-selected spermatozoa than unselected samples.

Fresh bull semen has also been prepared by SLC, using the scaled-up variant of a bovine-specific colloid in $50 \mathrm{~mL}$ tubes. Sperm chromatin integrity was reported to be improved in SLC samples compared to controls [59], although sperm motility was only improved in a haemospermic sample [60]. In other studies, a higher proportion of spermatozoa with high mitochondrial membrane potential was observed in the SLC samples than in controls [61]. Superoxide production was also increased; these two parameters indicate that the metabolic activity of the spermatozoa in the SLC samples may be increased compared to controls [61].

\subsection{Improving Cryosurvival}

In some species, such as cattle, the AI industry depends on cryopreserved semen. Cryopreservation not only prolongs the life of the semen sample and enables it to be transported around the world for insemination into females in other countries; it also permits the semen to be "quarantined" until the donors have been shown to be free of disease at the time of semen collection. However, spermatozoa are easily damaged by the processes of freezing and thawing, despite the addition of cryoprotectants; thus the sperm quality of thawed semen may be poor and the resulting pregnancy rate low. At the present time, success with freezing stallion and boar semen is not as good as with bull semen, with the result that the equine and swine breeding industries rely mostly on fresh (usually cooled) semen.

Selection of stallion and boar spermatozoa by SLC prior to cryopreservation results in better sperm quality in the thawed samples than in unselected controls e.g. stallion [42]; boar [62] [63]. The SLC-selected sperm samples survived longer after thawing than control samples [64]. However, using a different colloid, Mancill et al. [65] were unable to show a difference in pregnancy rates compared to controls when colloid-centrifuged stallion semen was frozen and subsequently used for AI. Clearly further research is needed to optimize the protocols.

\subsection{Preparing Spermatozoa for in Vitro Fertilization or ICSI}

The most frequently reported application for SLC in animal assisted reproduction is in preparing thawed sperm samples for IVF e.g. [66]. In this application, the spermatozoa have to be separated from the cryoextender in which the semen was frozen, and from seminal plasma that contains decapacitation factors. Selection of spermatozoa with normal morphology and intact membranes is associated with increased blastocyst formation and quality. It is not only the ability of the spermatozoa to penetrate and activate the oocyte that is important but also the ability of the zygote to continue to develop; chromatin integrity is implicated in this process. The advantages of SLC over "swim-up" are that the selection is not just based on motility, but also on other attributes of sperm quality, the procedure is quicker than for "swim-up" and a higher yield of spermatozoa is recovered. Stallion spermatozoa have been prepared for ICSI using SLC [67].

\subsection{Conservation Breeding}

Sperm quality may be a problem in rare breeds [68], particularly since there are a limited number of males from which to choose, and they will not have been selected for sperm quality. Thus, SLC can be useful either in selecting good quality spermatozoa prior to cryopreservation or in processing the thawed sperm samples. There have been reports of the use of SLC to improve sperm quality in several rare species: e.g. goats [69]; donkey [70]; brown bear [71], and domestic cat as a model for wild species [72]. Use of SLC with thawed sperm samples is more appropriate for IVF than for AI in the field but is theoretically possible for the latter if there is access to a centrifuge.

As mentioned previously, epididymal or testicular spermatozoa can be purified by SLC e.g. cat [73]; stallion 
[5]. A similar method has been used to prepare wolf spermatozoa free of somatic cells for DNA extraction [74].

\subsection{Potential Applications for Non-Reproductive Cells}

Since silane-coated silica is non-cytotoxic, colloid centrifugation could potentially be used for other types of cells, such as stem cells and immune cells, as well as female reproductive cells. The composition of the salt solution used to dilute the colloid should be altered to suit the types of cells to be selected, and the $\mathrm{pH}$ and osmolarity adjusted. The density of the colloid should also be optimized for the particular cell type, depending on the application.

\section{Conclusion}

Of the various techniques available for selecting spermatozoa for ART, colloid centrifugation has the greatest potential for selecting spermatozoa with the desired attributes for fertilization and embryo development. In addition, good recovery rates can be obtained by paying attention to the physical and chemical properties of the colloids to be used, and considering the physical properties of the semen to be processed. The recovery rate of good quality spermatozoa is higher than other techniques. Colloid centrifugation, particularly SLC, offers many advantages for improving sperm quality for ART, such as selecting motile spermatozoa with normal morphology, intact membranes and good chromatin integrity. These spermatozoa have improved fertilizing ability compared to unselected spermatozoa. Colloid centrifugation has a range of applications for different species, including prolonging the usable life of fresh or cooled semen samples, and improving cryosurvival. The procedure is straightforward and quick to perform, can be used by the personnel on most stud farms or semen collection stations where there is a swing-out centrifuge, and in IVF laboratories; a similar technique may be used for other types of reproductive cells, such as spermatids or spermatogonia for germplasm banking, or may be used to select non-reproductive cells.

\section{Acknowledgements}

We are grateful to all the colleagues, too numerous to mention individually, who have helped with many of the studies presented in this review. Much of the work was financed by grants from the Swedish Foundation for Equine Research, Stockholm, The Swedish Research Council for Environment, Agricultural Sciences and Spatial Planning (FORMAS), The Swedish Research Council (VR) and the Swedish Farmers' Association, Stockholm, Sweden, awarded to the authors.

\section{References}

[1] Pertoft, H. (2000) Fractionation of Cells and Subcellular Particles with Percoll. Journal Biochem. Biophysical Methods, 44, 1-30. http://dx.doi.org/10.1016/S0165-022X(00)00066-X

[2] Morrell, J.M. (2011) Artificial Insemination: Current and Future Trends. INTECH Open Access Publisher, Croatia. InTech. http://www.intechopen.com/articles/show/title/artificial-insemination-current-and-future-trends

[3] Morrell, J.M. and Rodriguez-Martinez, H. (2009) Biomimetic Techniques for Improving Sperm Quality in Animal Breeding: A Review. The Open Andrology Journal, 1, 1-9.

[4] Sakkas, D., Ramalingam, M., Garrido, N. and Barratt, C.L.R. (2015) Sperm Selection in Natural Conception: What Can We Learn from Mother Nature to Improve Assisted Reproduction Outcomes? Human Reproduction Update, 21, 711-726. http://dx.doi.org/10.1093/humupd/dmv042

[5] Santos, F.C.C., Curcio, B.R, Nunes, M.M., Morrell, J.M. and Malschitzky, E. (2016) Effect of Single Layer Centrifugation on Motility of Epididymal Stallion Sperm— Preliminary Data. In Press.

[6] Ock, S.-A., Lee, A.-L., Jeon, B.-G., Cho, S.-R., Kumar, B.M., Choi, Y.-S., Choe, S.-Y. and Rho, G.-J. (2006) Isolation and Viability of Presumptive Spermatids Collected from Bull Testes by Percoll Density Gradients. Animal Reproduction Science, 93, 144-156. http://dx.doi.org/10.1016/j.anireprosci.2005.07.011

[7] Roth, T.L., Stoops, M.A. and Robeck, T.R. (2016) Factors Impacting the Success of Post-Mortem Sperm Rescue in the Rhinoceros. Animal Reproduction Science, 167, 22-30. http://dx.doi.org/10.1016/j.anireprosci.2016.01.019

[8] Herrid, M. and MacFarlane, J. (2013) Application of Testis Germ Cell Transplantation in Breeding Systems of Food Producing Species: A Review. Animal Biotechnology, 24, 293-306. http://dx.doi.org/10.1080/10495398.2013.785431

[9] Morrell, J.M., Johannisson, A., Dalin, A.-M. and Rodriguez-Martinez, H. (2009) Morphology and Chromatin Integrity 
of Stallion Spermatozoa Prepared by Density Gradient and Single Layer Centrifugation through Silica Colloids. Reproduction Domestic Animals, 44, 512-517. http://dx.doi.org/10.1111/j.1439-0531.2008.01265.x

[10] Morrell, J.M., Johannisson, A., Dalin, A.-M., Hammar, L., Sandebert, T. and Rodriguez-Martinez, H. (2008) Sperm Morphology and Chromatin Integrity in Swedish Warm Blood Stallions and Their Relationship to Pregnancy Rates. Acta Veterinaria Scandinavica, 50, 2-8. http://dx.doi.org/10.1186/1751-0147-50-2

[11] Suarez, S. (2007) Interactions of Spermatozoa with the Female Reproductive Tract: Inspiration for Assisted Reproduction. Reproduction, Fertility and Development, 19, 103-110. http://dx.doi.org/10.1071/rd06101

[12] Hunter, R.H. and Rodriguez-Martinez, H. (2002) Analysing Mammalian Fertilisation: Reservations and Potential Pitfalls with an in Vitro Approach. Zygote, 10, 11-15. http://dx.doi.org/10.1017/S0967199402002022

[13] Yang, Q., Zhang, N., Zhao, F., Zhao, W., Dai, S., Liu, J., Bukhari, I., Xin, H., Niu, W. and Sun, Y. (2015) Processing of Semen by Density Gradient Centrifugation Selects Spermatozoa with Longer Telomeres for Assisted Reproduction Techniques. Reproductive BioMedicine Onlinee, 31, 44-50. http://dx.doi.org/10.1016/j.rbmo.2015.02.016

[14] Morrell, J.M., Johannisson, A. and Rodriguez-Martinez, H. (2011) Effect of Osmolarity and Density of Colloid Formulations on the Outcome of SLC-Selection of Stallion Spermatozoa. ISRN Veterinary Science, 2011, 5 p. http://dx.doi.org/10.5402/2011/128984

[15] Morrell, J.M., Dalin, A.-M. and Rodriguez-Martinez, H. (2009) Comparison of Density Gradient and Single Layer Centrifugation of Stallion Spermatozoa: Yield, Motility and Survival. Equine Veterinary Journal, 41, 53-58. http://dx.doi.org/10.2746/042516408X322139

[16] Morrell, J.M., Rodriguez-Martinez, H. and Johannisson, A. (2010) Single Layer Centrifugation of Stallion Spermatozoa Consistently Selects the Most Robust Spermatozoa from the Rest of the Ejaculate in a Large Sample Size: Data from 3 Breeding Seasons. Equine Veterinary Journal, 42, 579-585. http://dx.doi.org/10.1111/j.2042-3306.2010.00101.x

[17] Lindahl, J., Dalin, A.-M., Stuhtmann, G. and Morrell, J.M. (2012) Stallion Spermatozoa Selected by Single Layer Centrifugation Are Capable of Fertilization after Storage for up to $96 \mathrm{~h}$ at $6^{\circ} \mathrm{C}$ Prior to Artificial Insemination. Acta Veterinaria Scandinavica, 54, 40-45. http://dx.doi.org/10.1186/1751-0147-54-40

[18] Heutelbeck, A., Oldenhof, H., Rohn, K., Martinsson, G., Morrell, J.M. and Sieme, H. (2015) Use of Density Centrifugation for Delayed Cryopreservation of Stallion Sperm: Perform Sperm Selection Directly after Collection or after Storage? Reproduction in Domestic Animals, 50, 76-83. http://dx.doi.org/10.1111/rda.12451

[19] Bolton, V.N. and Braude, P.R. (1984) Preparation of Human Spermatozoa for in Vitro Fertilization by Isopycnic Centrifugation on Self-Generating Density Gradients. Archives of Andrology, 13, 167-176. http://dx.doi.org/10.3109/01485018408987515

[20] Parrish, J.J., Krogenaes, A. and Susko-Parrish, J.L. (1995) Effect of Bovine Sperm Separation by Either Swim-Up or Percoll Method on Success of in Vitro Fertilization and Early Embryonic Development. Theriogenology, 44, 859-869. http://dx.doi.org/10.1016/0093-691X(95)00271-9

[21] Avery, B. and Greve, T. (1995) Impact of Percoll on Bovine Spermatozoa Used for in Vitro Insemination. Theriogenology, 44, 871-878. http://dx.doi.org/10.1016/0093-691X(95)00272-A

[22] Motoishi, M., Goto, K., Tomita, K., Ookutsu, S. and Nakanushi, Y. (1996) Examination of the Safety of Intracytoplasmic Injection Procedures by Using Bovine Oocytes. Human Reproduction, 11, 618-620. http://dx.doi.org/10.1093/HUMREP/11.3.618

[23] Mizuno, K., Hoshi, K. and Huang, T. (2002) Fertilization and Embryo Development in a Mouse ICSI Model Using Human and Mouse Sperm after Immobilisation in Polyvinlypyrrolidone. Human Reproduction, 17, 2350-2355. http://dx.doi.org/10.1093/humrep/17.9.2350

[24] Balaban, B., Lundin, K., Morrell, J.M., Tjellström, H., Urman, B. and Holmes, P.V. (2003) An Alternative to PVP for Slowing Sperm Prior to ICSI. Human Reproduction, 18, 1887-1889. http://dx.doi.org/10.1093/humrep/deg385

[25] Mortimer, D. (2000) Sperm Preparation Methods. Journal of Andrology, 21, 357-366.

[26] Strehler, E., Baccetti, B., Sterzik, K., Capitani, S., Collodel, G., De Santo, M., Gambera, L. and Piomboni, P. (1998) Detrimental Effects of Polyvinylpyrrolidone on the Ultrastructure of Spermatozoa (Notulae Seminologicae 13). Human Reproduction, 13, 120-123. http://dx.doi.org/10.1093/humrep/13.1.120

[27] Macpherson, M., Blanchard, T.L., Love, C.C., Brinsko, S.P., Thompson, J.A. and Varner, D.D. (2002) Use of a Silane-Coated Silica Particle Solution to Enhance the Quality of Ejaculated Semen in Stallions. Theriogenology, 58, 317320. http://dx.doi.org/10.1016/S0093-691X(02)00736-7

[28] Varner, D.D., Love, C.C., Brinsko, S.P., Blanchard, T.L.,Hartman, D.L., Bliss, S.B., Carroll, B.S. and Eslick, M.C. (2008) Semen Processing for the Sub-Fertile Stallion. Journal Equine Veterinary Science, 28, 677-685.

http://dx.doi.org/10.1016/j.jevs.2008.10.012 
[29] Sharma, R.K., Seifarth, K. and Agarwal, A. (1997) Comparison of Single- and Two-Layer Percoll Separation for Selection of Motile Spermatozoa. International Journal of Fertility and Women's Medicine, 42, 412-417.

[30] Sieme, H., Martinsson, G., Rauterberg, H., Walter, K., Aurich, C., Petzoldt, R. and Klug, E. (2003) Application of Techniques for Sperm Selection in Fresh and Frozen-Thawed Stallion Semen. Reproduction in Domestic Animals, 38, 134-140. http://dx.doi.org/10.1046/j.1439-0531.2003.00416.x

[31] Morrell, J.M., Dalin, A.-M. and Rodriguez-Martinez, H. (2008) Prolongation of Stallion Sperm Survival by Centrifugation through Coated Silica Colloids: A Preliminary Study. Animal Reproduction, 5, 121-126.

[32] Morrell, J.M., Johannisson, A., Dalin, A-M. and Rodriguez-Martinez, H. (2009) Single Layer Centrifugation with Androcoll-E Can Be Scaled-Up to Allow Large Volumes of Stallion Ejaculate to Be Processed Easily. Theriogenology, 72, 879-884. http://dx.doi.org/10.1016/j.theriogenology.2009.05.015

[33] Morrell, J.M., van Wienen, M. and Wallgren, M. (2011) Single Layer Centrifugation Can Be Scaled-Up Further to Process up to $150 \mathrm{~mL}$ Semen. ISRN Veterinary Science, 2011, Article ID: 183412. http://dx.doi.org/10.5402/2011/183412

[34] Morrell, J.M. (2012). Stallion Sperm Selection: Past, Present and Future Trends. Journal of Equine Veterinary Science, 32, 436-440. http://dx.doi.org/10.1016/j.jevs.2012.05.069

[35] Anel-López, L., Martínez-Rodríguez, C., Soler, A.J., Fernández-Santos, M.R., Garde, J.J. and Morrell, J.M. (2015) The Use of Androcoll-S after Thawing Improves the Quality of Electroejaculated and Epididymal Sperm Samples from Red Deer. Animal Reproduction Science, 158, 68-74. http://dx.doi.org/10.1016/j.anireprosci.2015.04.009

[36] Abraham, M.C., Johannisson, A. and Morrell, J.M. (2016) Effect of Sperm Preparation on Development of Bovine Blastocyst in Vitro. Zygote, In Press.

[37] Morrell, J.M., Lagerquist, A., Humblot, P. and Johannisson, A. (2016) Effect of Single Layer Centrifugation on Reactive Oxygen Species and Sperm Mitochondrial Membrane Potential in Cooled Stallion Semen. Reproduction Fertility and Development, In Press. http://dx.doi.org/10.1071/RD15440

[38] Varner, D.D., Blanchard, T.L., Love, C.C., Garcia, M.C. and Kenney, R.M. (1987) Effects of Semen Fractionation and Dilution Ratio on Equine Spermatozoal Motility Parameters. Theriogenology, 28, 709-723. http://dx.doi.org/10.1016/0093-691X(87)90288-3

[39] Björndahl, L., Mohammadiehl, M., Pourian, M., Söderlund, I. and Kvist, U. (2005) Contamination by Seminal Plasma Factors during Sperm Selection Journal of Andrology, 26, 170-173. http://dx.doi.org/10.1002/j.1939-4640.2005.tb01080.x

[40] Hallap, T., Håård, M., Jaakma, U., Larsson, B. and Rodriguez-Martinez, H. (2004) Does Cleansing of Frozen-Thawed Bull Semen before Assessment Provide Samples That Relate Better to Potential Fertility? Theriogenology, 62, 702-713. http://dx.doi.org/10.1016/j.theriogenology.2003.11.017

[41] Loomis, P.R. (2006) Advanced Methods for Handling and Preparation of Stallion Semen. Veterinary Clinics of North America: Equine Practice, 22, 663-676. http://dx.doi.org/10.1016/j.cveq.2006.07.002

[42] Hoogewijs, M., Morrell, J.M., Van Soom, A., Govaere, J., Johannisson, A., Piepers, P., de Schauwer, C., de Kruif, A. and de Vliegher, S. (2011) Sperm Selection Using Single Layer Centrifugation Prior to Cryopreservation Can Increase Post Thaw Sperm Quality in Stallions. Equine Veterinary Journal, 43, 35-41. http://dx.doi.org/10.1111/j.2042-3306.2011.00489.x

[43] Fraser, L., Dziekonska, A., Strzezek, R. and Strzezek, J. (2007) Dialysis of Boar Semen Prior to Freezing-Thawing: Its Effects on Post-Thaw Sperm Characteristics. Theriogenology, 67, 994-1003. http://dx.doi.org/10.1016/j.theriogenology.2006.12.002

[44] Neto, C.R., Monteiro, G.A., Soares, R.F., Pedrazzi, C., Delláqua Jr., J.A., Papa, F.O. and Alvarenga, M.A. (2013) Effect of Removing Seminal Plasma Using a Sperm Filter on the Viability of Refrigerated Stallion Semen. Journal Equine Veterinary Sciences, 33, 40-43. http://dx.doi.org/10.1016/j.jevs.2012.04.008

[45] Somfai, T., Bodo, S., Nagy, S., Papp, A.B., Ivancsics, J., Baranyai, B., Gocza, E. and Kovacs, K. (2002) Effect of Swim-Up and Percoll Treatment on Viability and Acrosome Integrity of Frozen-Thawed Bull Spermatozoa. Reproduction in Domestic Animals, 37, 285-290. http://dx.doi.org/10.1046/j.1439-0531.2002.00350.x

[46] Shamsuddin, M. and Rodriguez-Martinez, H. (1994) A Simple, Non-Traumatic Swim-Up Method for the Selection of Spermatozoa for in Vitro Fertilization in the Bovine. Animal Reproduction Science, 36, 61-75. http://dx.doi.org/10.1016/0378-4320(94)90054-X

[47] Saylan, A. and Duman, S. (2016) Efficacy of Hyaluronic Acid in the Selection of Human Spermatozoa with Intact DNA by the Swim-Up Method. Cell Journal, 18, 83-88.

[48] Mogas, T., Rigau, T., Piedrafita, J., Bonet, S. and Rodriguez-Gil, J.E. (1998) Effect of Column Filtration upon the Quality Parameters of Fresh Dog Semen. Theriogenology, 50, 1171-1189.

http://dx.doi.org/10.1016/S0093-691X(98)00218-0 
[49] Bussallou, E., Pinart, E., Rivera, M.M., Arlas, X., Briz, M., Sancho, S., Garcia-Gil, N., Bassols, J., Prunedo, A., Yeste, M., Casas, I., Rigau, T., Rodriguez-Gil, J.E. and Bonet, S. (2008) Effects of Filtration of Semen Doses from Subfertile Boars through Neuter Sephadex Columns. Reproduction in Domestic Animals, 43, 48-52.

[50] Ahmad, Z., Anzar, M., Shahab, M., Ahmad, N. and Andrabi, S.M.H. (2003) Sephadex and Sephadex Ion-Exchange Filtration Improves the Quality and Freezability of Low-Grade Buffalo Semen Ejaculates. Theriogenology, 59, 11891202. http://dx.doi.org/10.1016/S0093-691X(02)01159-7

[51] Samper, J.C., Hamilton, D.W., Pryor, J.L., Loseth, K.J., Troedsson, M.H.T. and Crabo, B.G. (1995) Mechanism of Sephadextraping of Capacitated Stallion Spermatozoa. Biology of Reproduction, 729-737.

[52] Januskauskas, A., Lukosevicuie, K., Nagy, S., Johannisson, A. and Rodriguez-Martinez, M. (2005) Assessment of the Efficacy of Sephadex G-15 Filtration of Bovine Spermatozoa for Cryopreservation. Theriogenology, 63, 160-178. http://dx.doi.org/10.1016/j.theriogenology.2004.04.002

[53] Henkel, R.R. and Schill, W.-B. (2003) Sperm Preparation for ART. Reproductive Biology and Endocrinology, 1, 108142. http://dx.doi.org/10.1186/1477-7827-1-108

[54] Rappa, K.L., Rodriguez, H.F., Hakkarainen, G.C., Anchan, R.M., Mutter, G.L. and Asghar, W. (2016) Sperm Processing for Advanced Reproductive Technologies: Where Are We Today? Biotechnology Advances, 34, 578-587. http://dx.doi.org/10.1016/j.biotechadv.2016.01.007

[55] Kishi, K., Ogata, H., Ogata, S., Mizusawa, Y., Okamoto, E., Matsumoto, Y., Kokeguchi, S. and Shiotani, M. (2015) Frequency of Sperm DNA Fragmentation According to Selection Method: Comparison and Relevance of a Microfluidic Device and a Swim-Up Procedure. Journal of Clinical and Diagnostic Research, 9, QC14-QC16. http://dx.doi.org/10.7860/jcdr/2015/10332.6811

[56] Morrell, J.M. (2011) Biomimetics in Action: Practical Applications of Single Layer Centrifugation for Equine Breeding. Veterinary Science and Technology, 2, 107.

[57] Morrell, J.M., Richter, J., Martinsson, G., Stuhtmann, G., Hoogewijs, M., Roels, K. and Dalin, A.-M. (2014) Pregnancy Rates Are Higher after Artificial Insemination with Cooled Stallion Spermatozoa Selected by Single Layer Centrifugation Than with Control Semen Doses. Theriogenology, 82, 1102-1105. http://dx.doi.org/10.1016/j.theriogenology.2014.07.028

[58] Johannisson, A., Morrell, J.M., Thorén, J, Jonsson, M., Dalin, A-M. and Rodriguez-Martinez, H. (2009) Colloidal Centrifugation with Androcoll-Eт Prolongs Stallion Sperm Motility, Viability and Chromatin Integrity. Animal Reproduction Science, 116, 119-128. http://dx.doi.org/10.1016/j.anireprosci.2009.01.008

[59] Goodla, L., Morrell, J.M., Yusnizar, Y., Stalhammar, H. and Johannisson, A. (2014) Quality of Bull Spermatozoa after Preparation by Single Layer Centrifugation. Journal Dairy Science, 97, 2204-2212. http://dx.doi.org/10.3168/jds.2013-7607

[60] Yusnizar, Y., Abraham, M.C., Laskowski, D., Johannisson, A. and Morrell, J.M. (2014) Changes in Bull Sperm Kinematics after Single Layer Centrifugation. Reproduction in Domestic Animals, 49, 954-956. http://dx.doi.org/10.1111/rda.12412

[61] Johannisson, A., Nongbua, T. and Morrell, J.M. (2016) Effects of Single Layer Centrifugation (SLC) on Bull Spermatozoa Prior to Freezing on Post-Thaw Semen Characteristics. In Press.

[62] Martinez-Alborcia, M.J., Morrell, J.M., Parrilla, I., Barranco, I., Vázquez, J.M., Martinez, E.A. and Roca, J. (2012) Improvement of Boar Sperm Cryosurvival by Using Single-Layer Colloid Centrifugation Prior Freezing. Theriogenology, 78, 1117-1125. http://dx.doi.org/10.1016/j.theriogenology.2012.05.008

[63] Martinez-Alborcia, M.J., Morrell, J.M., Barranco, I., Maside, C., Gil, M.A., Parrilla, I., Vazquez, J.M., Martinez, E.A. and Roca, J. (2013) Suitability and Effectiveness of Single Layer Centrifugation Using Androcoll-P in the Cryopreservation Protocol for Boar Spermatozoa. Animal Reproduction Science, 140, 173-179. http://dx.doi.org/10.1016/j.anireprosci.2013.06.015

[64] Hoogewijs, M., Piepers, S., Govaere, J., de Schauwer, C., de Kruif, A.,m Morrell, J.M. (2012) Sperm Longevity Following Pre-Freeze Sperm Selection. Journal Equine Veterinary Science, 32, 489. http://dx.doi.org/10.1016/j.jevs.2012.06.048

[65] Mancill, S.S., Love, C.C., Brinsko, S.P., Edmond, A.J., Foster, M.L., Teague, S.R,, Waite, J.A. and Varner, D.D. (2010) Effect of Density Gradient Centrifugation on Cryopreservation of Equine Spermatozoa. Animal Reproduction Science, 1215, S208-S209.

[66] Thys, M., Vandaele, L., Morrell, J.M., Mestach, J., Van Soom, A., Hoogewijs, M. and Rodriguez-Martinez, H. (2009) In Vitro Fertilizing Capacity of Frozen-Thawed Bull Spermatozoa Selected by Single-Layer (Glycidoxypropyltrimethoxysilane) Silane-Coated Silica Colloidal Centrifugation. Reproduction in Domestic Animals, 44, 390-394. http://dx.doi.org/10.1111/j.1439-0531.2008.01081.x

[67] Colleoni, S., Lagutina, I., Rodriguez-Martinez, H., Lazzari, G., Galli, C. and Morrell, J.M. (2011) New Techniques for 
Selecting Spermatozoa for Equine Assisted Reproduction. Journal Equine Veterinary Science, 31, 536-541. http://dx.doi.org/10.1016/j.jevs.2011.03.009

[68] Woelders, H., Windig, J. and Hiemstra, S.J. (2012) How Developments in Cryobiology, Reproductive Technologies and Conservation Genomics Could Shape Gene Banking Strategies for (Farm) Animals. Reproduction in Domestic Animals, 47, 264-273. http://dx.doi.org/10.1111/j.1439-0531.2012.02085.x

[69] Jiménez-Rabadán, P., Morrell, J.M., Johannisson, A., Ramón, M., García-Álvarez, O., Maroto-Morales, A., Alvaro-García, P.J., Pérez-Guzmán, M.D., Fernández-Santos, M.R., Garde, J.J. and Soler, A.J. (2012) Single Layer Centrifugation (SLC) Improves Sperm Quality of Cryopreserved Blanca-Celtibérica Buck Semen. Animal Reproduction Science, 136, 47-54. http://dx.doi.org/10.1016/j.anireprosci.2012.09.012

[70] Ortiz, I., Dorado, J., Morrell, J.M., Crespo, F., Gosalvez, J., Gálvez, M.J., Acha, D. and Hidalgo, M. (2015) Effect of Single Layer Centrifugation or Washing on Frozen-Thawed Donkey Semen Quality: Do They Have the Same Effect Regardless of the Quality of the Sample? Theriogenology, 84, 294-300.

http://dx.doi.org/10.1016/j.theriogenology.2015.03.021

[71] Alvarez-Rodriguez, M., Alvarez, M., Anel-Lopez, L., Lopez-Ursena, E., Manrique, P., Borregan, S., Morrell, J.M., de Paz, P. and Anel, L. (2016) Effect of Colloid (Androcoll-Bear, Percoll and PureSperm) Selection on the Freezability of Brown Bear (Ursusarctos Sperm). Theriogenology, 85, 1097-1105. http://dx.doi.org/10.1016/j.theriogenology.2015.11.021

[72] Chatdarong, K., Thuwanut, P. and Morrell, J.M. (2010) Single-Layer Centrifugation through Colloid Selects Improved Quality of Epididymal Cat Sperm. Theriogenology, 73, 1284-1292. http://dx.doi.org/10.1016/j.theriogenology.2009.12.009

[73] Chatdarong, K., Thuwanut, P. and Morrell, J.M. (2016) The Development of Cat Testicular Sperm Cryopreservation Protocols: effects of Tissue Fragments or Sperm Cell Suspensions. Theriogenology, 85, 200-206. http://dx.doi.org/10.1016/j.theriogenology.2015.09.030

[74] Muñoz-Fuentes, V., LindeForsberg, C., Vilà, C. and Morrell, J.M. (2014) Single Layer Centrifugation Separates Spermatozoa from Diploid Cells in Epididymal Samples from Grey Wolves, Canis lupus (L.). Theriogenology, 82, 773-776. http://dx.doi.org/10.1016/j.theriogenology.2014.04.029

[75] Morrell, J.M. and Wallgren, M. (2011) Colloid Centrifugation of Boar Semen. Reproduction in Domestic Animals, 46, 18-22. http://dx.doi.org/10.1111/j.1439-0531.2011.01866.x

[76] Goyal, R.L., Tuli, R.K., Georgie, G.C. and Chand, D. (1996) Comparison of Quality and Freezability of Water Buffalo Semen after Washing or Sephadex Filtration. Theriogenology, 46, 679-686. http://dx.doi.org/10.1016/0093-691X(96)00219-1

[77] Marti, E., Perez-Pe, R., Muino-Blanco, T. and Cebrian-Perez, J.A. (2006) Comparative Study of Four Different Sperm Washing Methods Using Apoptotic Markers in Ram Semen. Journal of Andrology, 27, 746-753. http://dx.doi.org/10.2164/jandrol.106.000109

[78] Correa, J.R. and Zavos, P.M. (1996) Preparation and Recovery of Frozen-Thawed Bovine Spermatozoa via Various Sperm Selection Techniques Employed in Assisted Reproductive Technologies. Theriogenology, 46, 1225-1232. http://dx.doi.org/10.1016/S0093-691X(96)00293-2

[79] Garcia-Rosello, E., Mattas, C., Canovas, S., Moreira, P., Gadea, J. and Coy, P. (2006) Influence of Sperm Pretreatment on the Efficiency of Intracytoplasmic Sperm Injection in Pigs. Journal of Andrology, 27, 268-275. http://dx.doi.org/10.2164/jandrol.05110

[80] Pagl, R., Aurich, J.E., Müller-Schlösser, F., Kankofer, M. and Aurich, C. (2006) Comparison of an Extender Containing Defined Milk Protein Fractions with a Skim Milk-Based Extender for Storage of Equine Semen at $5^{\circ} \mathrm{C}$. Theriogenology, 66, 1115-1122. http://dx.doi.org/10.1016/j.theriogenology.2006.03.006

[81] Knop, K., Hoffmann, N., Rath, D. and Sieme, H. (2005) Effects of Cushioned Centrifugation Technique on Sperm Recovery and Sperm Quality in Stallions with Good and Poor Semen Freezability. Animal Reproduction Science, 89, 294-297.

[82] Cesari, A., Kaiser, G.G., Mucci, N., Mutto, A., Vincenti, A., Fornes, M.W. and Alberio, R.H. (2006) Integrated morphophysiological Assessment of Two Methods for Sperm Selection in Bovine Embryo Production in Vitro. Theriogenology, 66, 1185-1193. http://dx.doi.org/10.1016/j.theriogenology.2006.03.029

[83] Grasa, P., Perez-Pe, R., Baguena, O., Forcada, F., Abecia, A., Cebrian-Perez, J.A. and Muino-Blanco, T. (2004) Ram Sperm Selection by a Dextran/Swim-Up Procedure Increases Fertilisation Rates Following Intrauterine Insemination in Superovulated Ewes. Journal of Andrology, 25, 982-990. http://dx.doi.org/10.1002/j.1939-4640.2004.tb03171.x

[84] Mehmood, A., Anwar, M. and Naqvi, S.M. (2009) Motility, Acrosome Integrity, Membrane Integrity and Oocyte Cleavage Rate of Sperm Separated by Swim-Up or Percoll Gradient Method from Frozen-Thawed Buffalo Semen. Animal Reproduction Science, 111, 141-148. http://dx.doi.org/10.1016/j.anireprosci.2008.02.011 
[85] Zheng, Y.S., Fiser, P. and Sirad, M.A. (1992) The Use of Ejaculated Boar Semen After Freezing in 2\% or 6\% Glycerol for in Vitro Fertilization of Porcine Oocytes Matured in Vitro. Theriogenology, 38, 1065-1075. http://dx.doi.org/10.1016/0093-691X(92)90120-G

[86] Brahmkshtri, B.P., Edwin, M.J., Joshi, C.G., Sivaselvam, S.N. and Krishnan, A.R. (1997) Evaluation of Fertility Status of Murrah buffalo Bulls in Vitro Using Zona-Free Hamster Eggs. Theriogenology, 48, 501-512. http://dx.doi.org/10.1016/S0093-691X(97)00258-6

[87] Casey, P.J., Robertson, K.R., Lui, I.K.M., Espinoza, S.B. and Drobnis, E.Z. (1993) Column Separation of Motile Sperm from Stallion Semen. Journal of Andrology, 14, 142-148.

[88] Klinc, P., Kosec, M. and Majdic, G. (2005) Freezability of Equine Semen after Glass Beads Column Separation. Equine Veterinary Journal, 37, 43-47. http://dx.doi.org/10.2746/0425164054406810

[89] Graham, E.F. and Graham, J.K. (1990) The Effect of Whole Ejaculate Filtration on the Morphology and the Fertility of Bovine Semen. Journal of Dairy Science, 73, 91-97. http://dx.doi.org/10.3168/jds.S0022-0302(90)78650-X

[90] Anzar, M., Graham, E.F. and Iqbal, N. (1997) Post-Thaw Plasma Membrane Integrity of Bull Spermatozoa Separated with a Sephadex Ion-Exchange Column. Theriogenology, 47, 845-856. http://dx.doi.org/10.1016/S0093-691X(97)00040-X

[91] Popwell, J.M. and Flowers, W.L. (2004) Variability in Relationships between Semen Quality and Estimates of in Vivo and in Vitro Fertility in Boars. Animal Reproduction Science, 81, 97-113. http://dx.doi.org/10.1016/j.anireprosci.2003.08.007

[92] Brum, A.M., Sabeur, K. and Ball, B.A. (2008) Apoptotic-Like Changes in Equine Spermatozoa Separated by Density Gradient Centrifugation or after Cryopreservation. Theriogenology, 69, 1041-1055. http://dx.doi.org/10.1016/j.theriogenology.2008.01.014

[93] Morrell, J.M., Persson, B., Tjellström, H., Laessker, A., Nilsson, H., Danilova, M. and Holmes, P.V. (2005) Effect of Semen Extender and Density Gradient Centrifugation on the Motility and Fertility of Turkey Spermatozoa. Reproduction in Domestic Animals, 40, 522-525. http://dx.doi.org/10.1111/j.1439-0531.2005.00620.x

[94] Morrell, J.M., Rodriguez-Martinez, H. and Linde Forsberg, C. (2008) Single Layer Centrifugation on a Colloid Selects Motile and Morphologically Normal Spermatozoa from Dog Semen: Preliminary Results. Reproduction in Domestic Animals, 43, 61-68.

[95] Malo, C., Morrell, J.M., Crichton, E.G., Pukazhenthi, B.S. and Skidmore J.A. (2016) Use of Colloid Single Layer Centrifugation for Dromedary Camel Semen: Effect of Initial Dilution and Comparison of Two Colloids on Sperm Quality Parameters. Animal Reproduction Science, 169, 123. http://dx.doi.org/10.1016/j.anireprosci.2016.03.068

\section{Submit or recommend next manuscript to SCIRP and we will provide best service for you:}

Accepting pre-submission inquiries through Email, Facebook, LinkedIn, Twitter, etc.

A wide selection of journals (inclusive of 9 subjects, more than 200 journals)

Providing 24-hour high-quality service

User-friendly online submission system

Fair and swift peer-review system

Efficient typesetting and proofreading procedure

Display of the result of downloads and visits, as well as the number of cited articles

Maximum dissemination of your research work

Submit your manuscript at: http://papersubmission.scirp.org/ 